\title{
GASTRONOMI KULINER PERANAKAN NON-HALAL DI GLODOK, JAKARTA
}

\author{
Tanjung Prasetyo ${ }^{\mathbf{1}}$, Ni Luh Made Vinaya Medhiatika ${ }^{2}$ \\ Jurusan Manajemen, Fakultas Ekonomi dan Bisnis, Universitas Sahid \\ Jl.Prof. Dr. Soepomo, SH No.84 Tebet Jakarta Selatan \\ Email korespondensi : tanjungprasetyo@gmail.com
}

\begin{abstract}
ABSTRAK
Topik gastronomi menjadi pilihan karena ilmu ini sudah menjadi bagian dari pariwisata karena berkaitan dengan seni kuliner - makanan; yang sangat terkait erat dengan area atau tempat, identitas, dan budaya. Tujuan penelitian ini untuk menilik filosofi dari beragam kuliner nonhalal yang ada di Glodok, Jakaarta Barat. Metode deskriptif dengan uraian kualitatif digunakan peneliti untuk menjabarkan atas gambaran yang didapat saat turun lapangan. Hasil yang didapatkan bahwa filosofi, bumbu, rasa, dan tampilan untuk makanan seperti kuo tie, bakso, bakmi, dan sekba masih sama dengan asalnya dari Tionghoa. Pergeseran terjadi pada bakpia dimana yang dijual hanya rasa manis tanpa daging babi yang aman dikonsumsi masyarkat Indonesia. Filosofi dan alkulturasi budaya Tionghoa - Indonesia ini harus dipertahankan sehingga disarankan bagi penjual makanan untuk mempertahankan dan mempelajari ilmu gastronomi sehingga informasi yang diberikan akan semakin lengkap dan akurat. Penelitian ini bisa dilanjutkan untuk disiplin ilmu lain seperti ekonomi dan pariwisata gastronomi yang lebih mendalam.
\end{abstract}

Kata kunci : Gastronomi, filosofi, Peranakan, non-halal, Glodok

\begin{abstract}
Gastronomy, been choose as a current topic, because it's become part of tourism that related to culinary arts - food; that also connected to areas or places, identity, and culture. This research aimed to discover the philosophy of non-halal foods in Glodok, East Jakarta. Researcher use descriptive method with a qualitative writing to explain all objects that has been collected through field research. Results from this research discovered that philosophy, spices, flavors, and appearance from all of those foods (kuo tie, meatball, noodle, and sekba) are still the same as their original from Chinese culture. There's difference only in bakpia, where there is no longer filling with pork meat but only sweet flavors that suit Indonesian people religion. Advice for all of food vendors to keep learning about gastronomy so they can tell more information about these beautiful acculturations between Chinese philosophy of food and Indonesian culture for further research. This research also can be developing into another multidisciplinary such as economy and gastronomy tourism.
\end{abstract}

Keywords : gastronomy, philosophy, Peranakan, non-halal, Glodok 


\section{PENDAHULUAN}

Traveling atau bepergian bagi masyarakat Indonesia tidak hanya sekedar mengunjungi sebuah destinasi yang baru dan instagarmable. Berdasarkan data survei yang dilakukan oleh Booking.com di tahun 2018, hampir 73 persen masyarakat Indonesia memasukan agenda perjalanannya khusus untuk kuliner. Makanan tradisi Indonesia, miliki cita rasa sendiri diantaranya asin, manis dan pedas. Citarasa, penyajian dan pengolahan sangat dipengaruhi dari budaya yang ada di daerah tersebut. Akulturasi budaya, terjadi di Indonesia salah satu diantaranya adalah budaya etnis Tionghoa. Akulturasi budaya yang terjadi, berdampak salah satunya kepada produk makanan yang dihasilkan sehingga tanpa disadari menjadi khas kuliner suatu daerah, yang secara tidak langsung memperkaya resep, cita rasa dan jenis kuliner Nusantara. Kuliner Tionghoa Peranakan, miliki ciri cita rasa seperti; manis, asam, pahit, panas dan asin yang jika dikombinasikan akan menciptakan rasa manis - asin, panas -asam, panas sekali dan harum. Didapati pula ciri lain dari bau seperti, adas, cabai, kayu manis dan ciri dari unsur memotong bahan masakan dan teknik memasak yang sangat diperhatikan.

Terkait dengan wisata kuliner salah satunya tema yang bisa diangkat adalah gastronomi. Gastronomi merupakan segala ilmu berkaitan dengan seni kuliner makanan; yang sangat terkait erat dengan area atau tempat, identitas, dan budaya. "Kini dapat melihat gastronomi melalui sudut pandang foodscape (food \&landscape). Sudut pandang tersebut memberikan gambaran sosial, budaya, politik, ekonomi, serta sejarah yang terlihat melalui makanan. Riset yang dilakukan oleh Boyne, Williams, dan Hall -mengkonfirmasi adanya hubungan simbiosis mutualisme antara pariwisata dan kuliner. Periset menemukan bahwa wisatawan menghabiskan rata-rata hampir $30 \%$ dari anggaran untuk kebutuhan makanan (kuliner) saat berwisata. DKI Jakarta sendiri memiliki beraneka ragam daya tarik wisata, mulai dari daya tarik wisata alam seperti Ancol, daya tarik wisata sosial budaya seperti Taman Mini Indonesia Indah, dan daya tarik wisata minat khusus yang termasuk di dalamnya wisata belanja seperti Tanah Abang, hingga wisata kuliner. DKI Jakarta sekiranya pantas menjadi wisata gastronomi karena kuliner di DKI Jakarta sangat beragam. Sejarahnya sedari dahulu, Jakarta merupakan pintu masuk perdangangan. Semua pedagang dari Eropa, India, Arab, dan Tionghoa tidak hanya membawa barang dagangan tetapi juga menyebarkan budayanya termasuk lewat makanan. Jejak akulturasi kuliner budaya Tionghoa peranakan dapat ditemukan di kawasan khusus seperti Glodok atau Pecinan. Area seperti Petak Sembilan dan Gang Gloria menjadi tujuan utama para pemburu kuliner non-halal. Jenis kuliner non-halal di Glodok termasuk jenis makanan yang orisinil atau otentik. Jenis makanan Tionghoa non-halal antara lain; sekba Gloria, bakso babi bakmi Amoy, dan kuo tieh Santung 68.

Penelitian dari Gumulya (2017) menyatakan bahwa adanya akulturasi budaya Jawa, Belanda, dan Cina yang sangat unik. Sejarah dan keunikan dari budaya Cina Peranakan ini salah satunya terlihat dari budaya makan. Ilmu gastronomi tidak berdiri sendiri, melainkan ilmu dengan multi displin ilmu (multidisciplinary) seperti yang ditemukan oleh Zahari et al (2009) dalam Sormaz et al (2015) dimana hal tentang gastronomi (apa, dimana, bagaimana, kapan, mengapa, dengan siapa, dan siapa yang melakukan) dapat dikaitkan dengan ilmu; komunikasi, agrokultur, geografi, ekonomi, perdagangan, teknologi, filosofi, religi, moral, hukum, dan juga medis. Berdasarkan uraian ragam kuliner dan penelitian terdahulu, maka fokus penelitian ini akan pada filosofi gastronomi kuliner peranakan non-halal di Glodok, Jakarta Barat. 


\section{METODE PENELITIAN}

\section{Objek, lokasi, dan waktu}

Objek penelitian ini merupakan kuliner (makanan) non-halal berupa makanan ringan hingga makanan utama. Area penelitian akan dilakukan di area Glodok Waktu penelitian akan dilaksanakan bulan Maret 2019 hingga Maret 2020.

\section{Rancangan Penelitian}

Penelitian ini mengacu pada penelitian Pujawan dan Trisdayanti (2017) dimana metode penelitian yang akan digunakan adalah metode survei. Survei akan dilakukan dengan cara melakukan wawancara langsung kepada produsen yang membuat/menjual makanan untuk mendapatkan informasi mengenai nama makanan, bahan yang digunakan, serta proses pengolahan. Adapun sampling yang digunakan adalah teknik sampling jenuh (Sugiyono, 2015) yang merupakan teknik penentuan sampel bila semua anggota populasi digunakan sebagai sampel, teknik ini dilakukan bila jumlah populasi relatif kecil atau kurang dari 30 orang.

\section{Analisis Data}

Teknik analisis data pada penelitian ini dengan analisis deskriptif kualitatif, hasil wawancara di lapangan nantinya akan disusun kemudian dinarasikan secara deskriptif. Hasil analisis data akan disandingkan dengan teori dan hasil penelitian sebelumnya untuk mendapatkan pembahasan yang lebih mendalam.

\section{HASIL DAN PEMBAHASAN}

Pembahasan gastronomi untuk filosofi kuliner non-halal pada penelitian ini akan diawali dengan pembahasan tentang filosofi kuliner Tioghoa secara umum. Kuliner Tionghoa terkait perihal rasa, warna, dan bau dalam makanan sangat diperhatikan, baik dalam penyajian yang sederhana dan mewah sekalipun. Kuliner ini miliki cita rasa yang otentik daripada makanan lainnya. Otentisitas dapat dilihat dan dirasakan dalam seni memasak dan rasa masakan yang disajikan dengan sentuhan rasa otentik dari daerah asalnya. Mengenai rasa, yang dapat dikenali secara umum adalah rasa asin, manis dan asam sama seperti masakan pada umumnya. Dominasi campuran rasa sebagai otensitas masakan kuliner Peranakan itu sendiri notabene diperoleh dari asal domisili keturunan asli yang memasak dan dimana koki berada di luar daerah asal atau diperanakan. Mengenai rasa makanan yang dimaksud di atas yaitu rasa manis, asam, pahit, panas dan asin dan dapat dikombinasi untuk menciptakan rasa seperti manis - asin, panas - asam, panas sekali atau panas - harum. Tampilan sajian kuliner menjadi sesuatu yang memiliki makna secara psikologi bagi setiap yang melihat dan ingin menikmati sebuah sajian kuliner.

Tampilan sajian kuliner peranakan Tionghoa juga tidak terlepas dari faktor warna makanan. Tampilan sajian akan sama walaupun masakan itu sederhana bagi orang kebanyakan. Sajian kuliner peranakan Tionghoa biasanya didapati warna seperti warna merah, kuning, biru, putih dan hitam yang jika digabungkan akan meningkatkan selera makan. Semua warna yang disajikan ternyata juga memiliki nilai psikologis bagi penikmat kuliner. 
Perihal aroma dari kuliner Tionghoa dihasilkan dari 6 bumbu yang digunakan yaitu: (1) bubuk lima rempah (ngo hiong), (2) akar manis (gan cao), (3) andaliman (hua jiao), (4) moster (jie mo), (5) kayu manis cina (gui pi/rou gui), dan (6) kapulaga hitam (hei dou kou). Perpaduan semua rempah yang ada memiliki karakteristik rasa tersendiri, beberapa dapat dipadukan menjadi citarasa berbeda yang sedap agar yang menikmati setiap hidangan dapat mengalami sebuah pengalaman yang berbeda. Orisinilitas dan identitas kuliner peranakan Tionghoa tidak terlepas dari semua resep bumbu rempah yang sudah diturunkan leluhurnya secara turun temurun sebagai sebuah seni dalam memasak. Pengolahan kuliner peranakan Tionghoa juga terdapat tujuh kebutuhan bumbu atau bahan pelengkap dalam hal memasak diantaranya adalah; (1) kecap, (2) minyak goreng, (3) kayu bakar, (4) garam, (5) teh, (6) cuka, dan (7) unsur karbohidrat lainnya.

Pengolahan masakan pada etnis Tionghoa, selain memperhatikan unsur warna dan aroma juga sangat memperhatikan keahlian memotong bahan makanan serta kekuatan api yang dipadukan pada tehnik memasak. Kekuatan api dan teknik memasak, harus menjadi sesuatu kesatuan yang utuh dan kebiasaan dalam mengolahnya. Keahlian dalam memotong bahan makanan ini selalu memperhatikan cara penggunaan pisau, contohnya memotong bahan makanan lurus kebawah, menyamping, irisan lembut, irisan tipis tipis, memotong biasa, menusuk mengetuk atau mengerik. Terkait kekuatan api, juru masak sangat memperhatikan cepatnya api, diperbesar atau diperkecil. Memasak harus memperhatikan kekuatan dan pemilihan waktu api, karena hal tersebut mempengaruhi warna, bau dan juga rasa makanan. Teknik memasak pun juga memiliki cara, antara lain yaitu; mengukus, rebusan ganda, mengukus dengan kecap, merebus, menggoreng dengan mengaduk, menggoreng dengan sedikit minyak, menggoreng dengan minyak banyak, menggoreng secara cepat, merebus setelah menggoreng, menumis, memasak dengan sedikit air dan menutupnya.

Pembahasan selanjutnya akan masuk ke filosofi gastronomi dari kuliner non-halal di Glodok berdasarkan hasil turun lapangan peneliti. Kuliner yang akan dianalisis dimulai dari makanan ringan (kuo tie) hingga makanan penutup (bakpia). Pertama adalah kuo tie atau dengan kata lain adalah jiaozi. Sejarahnya, pencipta makanan ini secara legenda dibuat oleh Zhang Zhongjing [150-219 M] seorang ahli pengobatan dimasa akhir Dinasti Han. Makanan ini sudah ada sejak 1600 tahun yang lalu. Jiaozi pada asalnya dipanggal "Jiao Er" zaman dinasti Donghan (tahun 25-220 Masehi), penyakit berjangkit telah melanda pelbagai tempat di China. Zhang Zhongjing menggunakan tepung sebagai kulit Jiaozi yang diisi dengan daging kambing, cabai, dan obat herbal. Selepas memasaknya, beliau memberikan"Jiao Er" kepada para pesakitnya hingga hari terakhir tahun itu. Makanan ini terbukti dapat membantu banyak orang kembali menjadi sehat. Pada 1 bulan pertama imlek China, warga Tionghoa menyambuat Tahun Baru dan kemudian merayakan pula hari penyembuhan seperti sedia kala. Rakyat menggunakan tepung, daging dan sayur-sayuran sebagai mana yang digunakan dalam"Jiao Er" sambil memperingati Zhang Jingzhong. Hidangan ini merupakan makanan khas peranakan yang berasal dari kawasan Tiongkok Utara. Makanan ini di Indonesia biasa disajikan pada saat Imlek sebagai makanan utama, tetapi dalam keseharian sudah bergeser menjadi makanan pembuka atau camilan. Saat melakukan penelitian, pemilik kedai tengah bersiap menyiapkan bahan untuk memenuhi pesanan untuk perayaan Imlek. Makanan peranakan Tionghoa Utara ini masuk Indonesia diduga karena orang Tionghoa Utara dan Selatan sama-sama suka makan dan minum bersama keluarga terutama saat malam Imlek dan sebagai sajian menu utama. 
Menu Jiaozi sampai kapanpun akan terus di konsumsi sebagai sajian utama saat Imlek tanpa harus melihat asal usul mereka dari Utara ataupun Selatan dimana terdapat filosofi yang sederhana dari menu makanan sederhana ini karena menyerupai uang tael dengan harapan semoga bahagia dan kehidupan serba lancar pada tahun baru yang identik dengan makna membawa kemakmuran dan keberuntungan. Menu makanan ini disarankan dikonsumsi dalam keadaan hangat dengan cocolan saus sambal pedas, sehingga memberikan cita rasa tersendiri bagi siapapun yang menikmatinya. Versi menu ini dapat disajikan dalam 2 bentuk penyajian yaitu Panggang (sebutan Kuo Tie) dan basah/kukus (sebutan Siaw Kiaw). Hal ini dapat dibuktikan di Gambar 1 dan Gambar 2. Menu peranakan berasal dari Kota propinsi Tiongkok bagian Utara, Shandong/etnis Tionghoa Shantung. Lain halnya asal leluhur Tionghoa yang berada di Indonesia mayoritas adalah dari Tionghoa Selatan.

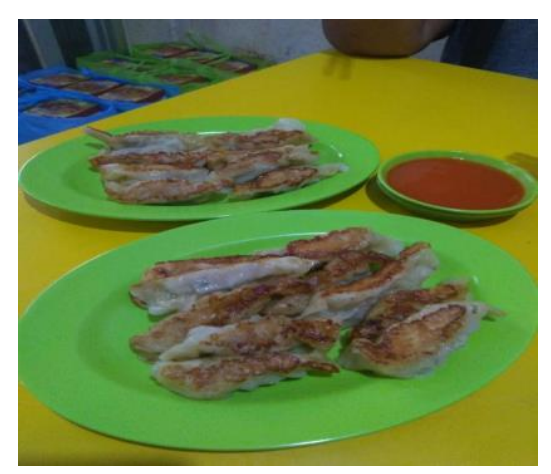

Gambar 1. Kuo Tie Akin

Gambar 1 di atas merupakan hidangan kuo tie dimana satu porsi kuo tie berisi 10 potong dan disajikan dengan saos sambal, cabai, bawang putih, dan kecap asin. Terkait tampilan menu adalah kombinasi putih- kecoklatan yang memiliki tekstur kulit tipis dengan dominasi rasa bawang putih yang sangat kuat, selain aroma kombinasi daun bawang dengan jahe serta daun kucai pada menu tersebut.

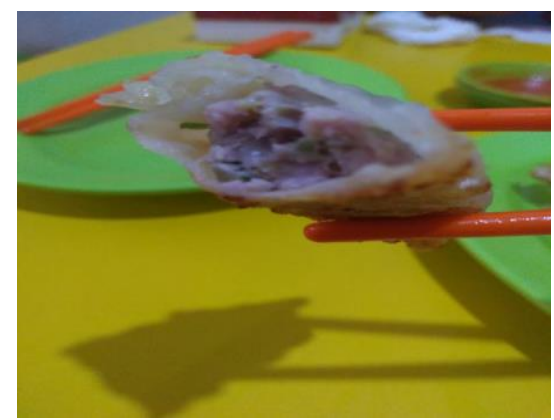

\section{Gambar 2. Isi Kuo Tie}

Gambar 2 menunjukkan isi kuo tie yang terdiri atas daging babi (harus bagian paha), sawi putih, bawang merah, dan bawang putih. Untuk kulitnya dibuat sendiri oleh sang pemilik. Teksturnya lembut dan gurih. Hasil wawancara singkat dengan pemilik, kuo tie ini harus menggunakan bagian paha karena bagian lain seperti perut atau kepala dagingnya berlemak dan lengket sehingga tidak bisa dibentuk bagus dengan kulitnya. Sejalan dengan sejarah di atas, pemilik kedai juga menjelaskan bahwa kuo tie dari berbagai daerah di Tiongkok memiliki isian yang berbeda, yang kami makan dijamin khas Santong/Shantung. 
Kuliner kedua berupa bakso dan bakmi. Sejarah bakso diawali awal abad ke-17 akhir dinasti Ming di Fuzhou Tiongkok sebagai bentuk bakti seorang anak namanya Meng Bo kepada ibunya yang sudah manula yang tidak dapat mengunyah makanan keras termasuk diantaranya daging babi. Terinspirasi melalui pembuatan kue mochi jadilah bakso dimana, untuk membuat makanan ini daging yang seharusnya alot dan berserat jadi empuk cocok untuk manula. Bakso masuk di Indonesia melalui Imigran dari Tiongkok yang datang ke Indonesia. Filosofi bakso dalam Bahasa Hokkien yang secara harfiah Bak-So berarti "daging giling" atau dua suku kata yakni Bak dan So dimana Bak berarti Daging babi dan So yang berarti kuah (kuah daging babi). Seiringan dengan perjalanan waktu, bakso bukan sebagai makanan khas imigrasi Tiongkok namun mulai diminati oleh penduduk lokal dan mulailah bakso terjadi perubahan resep masakan asli kepada resep masakan lokal, dimana penggunaan daging babi digantikan dengan daging lain seperti ayam, sapi, udang dan lainnya dimana unsur proteinnya tetap diperoleh dan yang pasti halal untuk dikonsumsi. Saat ini bakso menjadi makanan yang dapat dinikmati sebagai sebuah kudapan spesial yang berkuah sesuai cita rasa lokal Indonesia yang berbentuk bulat seperti aslinya. Gambar 3 berikut merupakan gambar bakso goreng yang menjadi andalan dari Bakmie Amoy yang peneliti sambangi.

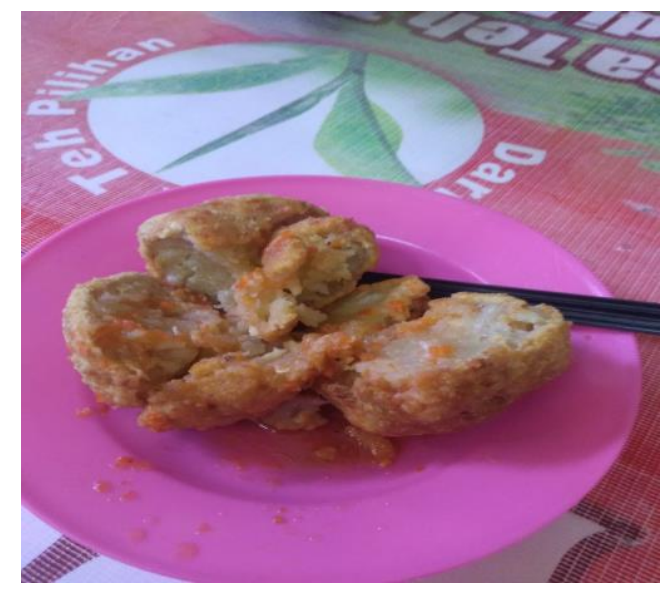

\section{Gambar 3. Bakso Goreng Bakmi Amoy}

Bakso goreng Bakmi Amoy ini bentuknya bulat seperti bola tenis, bulat mengembang yang dijual seharga 10.000 per buah. Bakso goreng dapat dinikmati dengan saos sambal khas Bakmi Amoy. Isian bakso goreng ini adalah campuran dari daging ayam, daging babi, dan udang. Camilan ini cocok untuk dimakan di tempat, sembari berjalan-jalan, atau dibawa pulang.

Pembahasan selanjutnya adalah teman setia bakso, yaitu bakmi. Sejarah bakmi di Tiongkok pertama kali dikonsumsi sekitar 206 SM terdapat pada Dinasti Han. Masyarakat Tiongkok sangat menyukai simbolisasi tidak telepas juga mengaitkan mie dengan simbol dari kehidupan yang panjang (abadi) atau panjang umur serta rejeki yang melimpah dan karenanya secara tradisional mie disajikan sebagai pengganti kue ulang tahun dengan harapan bisa panjang umur panjang dan memperoleh rejeki yang melimpah. Bakmi dipercaya dengan simbol panjang umur dan banyak rejeki maka kebanyakan masyarakat Tiongkok memakannya menggunakan sumpit dengan cara digulung ataupun disruput/disedot agar mienya tidak terputus. Bakmie kering yang menyerupai sarang burung juga memiliki filosofi keterkaitan dengan simbol ketekunan, kerja keras, dan sebagai tempat tinggal mereka. Menganalogikan Tiongkok sebagai 
sarang burungnya dan mempersiapkan keturunannya sebelum terbang keseluruh penjuru dunia dan sayuran, daging ayam, udang dan sayuran yang disiram diatasnya berupa kemakmuran. Filosofi tersebut berkat ketekunan, kerjakeras Tiongkok yang kering menjadi subur setelah disiram oleh kemakmuran yang diilustrasikan kuah diatas mie kering tersebut. Masuknya bakmi di Indonesia diperkirakan sama dengan kedatangan imigran dari Tiongkok yang datang ke Indonesia. Resep bakmi di Indonesia tidak jauh berbeda dengan bakmi resep peranakan namun dimodifikasi dalam bentuk penyajian dan penggunaan dagingnya. Peneliti mengambil sampel Bakmi Amoy untuk kajian ini. Berikut gambarnya:

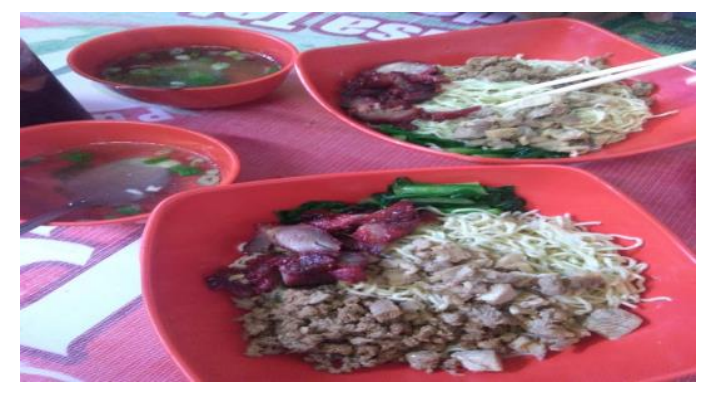

\section{Gambar 4 Bakmi Casiu di Bakmi Amoy}

Gambar 5 menampilkan bakmi casiu dilengkapi dengan topping daging ayam, daging babi cincang, casiu atau potongan daging babi merah, dan sawi. Kuahnya termasuk yang tidak terlalu kental yang merupakan kaldu babi. Bakmi yang digunakan cenderung tipis dan panjang. Pergeseran dari sejarah jelas terlihat bahwa bakmi bukan lagi sebagai sajian di ulang tahun atau hari besar namun sudah menjadi makanan seharihari bisa sebagai menu utama maupun pengganti menu utama (nasi). Bakmi Amoy sendiri menjadi bakmi yang direferensikan beberapa liputan kuliner. Kedai yang terletak dekat dengan kopi legendaris Tak Kie ini selalu ramai didatangi pengunjung, sehingga filosofi bakmi sebagai simbol rejeki yang berlimpah bisa dibuktikan disini.

Hidangan berikutnya, masih termasuk hidangan utama, dengan bahan dan rasa yang lebih otentik Peranakan yaitu sekba. Sekba atau kadang disebut juga sebagai bektim adalah hidangan khas yang direbus dalam kuah sup berbahan dasar kecap. Bumbu dan teknik khas Tionghoa sangat dibutuhkan pada hidangan ini. Hidangan rebusan ini mirip dengan semur, dan cita rasanya gurih, agak manis dan asin, dengan kuah yang terbuat dari kecap, bawang putih, dan bumbu-bumbu ramuan Tionghoa. Sejarah sekba adalah makanan kahas masakan Peranakan Tionghoa yang berisi jeroan daging babi seperti telinga, pipi, jantung, dan usus yang direbus dengan kuah kecap yang dipadukan dengan rempah asli Tionghoa. Cita rasa tradisional totok ini melebur disetiap sendok suapan sekba yang telah dikenal dan dijual sejak tahun 1950an. Keterbatasan refrensi dan informasi yang diperoleh mengenai menu peranakan ini dari penjual yang menyatakan bahwa ini hanya sebagai resep warisan keluarga Peranakan Tionghoa secara turun temurun. Beberapa yang dapat dipahami menu makanan ini sangat dipengaruhi oleh unsur masakan tradisional Peranakan yang beralkulturasi dengan masakan etnik Jawa dan Belanda (semur). Salah satu referensi budaya Tioghoa menyebutkan bahwa Masakan khas ini merupakan persilangan budaya Jawa dan Tionghoa yang sudah merupakan satu kesatuan dalam khasanah kuliner Nusantara. Masakan sekba atau bektim ini mirip dengan makanan babi cin. Komponen bumbu utamanya yaitu kencur, jinten/jintan dan bubuk ngo-hiong (ada yang menyebut ngo-hiang). Ngo-hiong sendiri merupakan dialek Hokkian, Khek, Tiociu yang semua mirip-mirip bunyinya, yang diambil dari kata wu xiang (五香; baca: wu siang), dalam 
bahasa Mandarin yang artinya 5 wewangian, yang dimaksud adalah komponen utama 5 macam bumbu sama seperti yang sudah dijabarkan sebelumnya. Berikut gambar sekba yang berhasil diliput oleh peneliti:

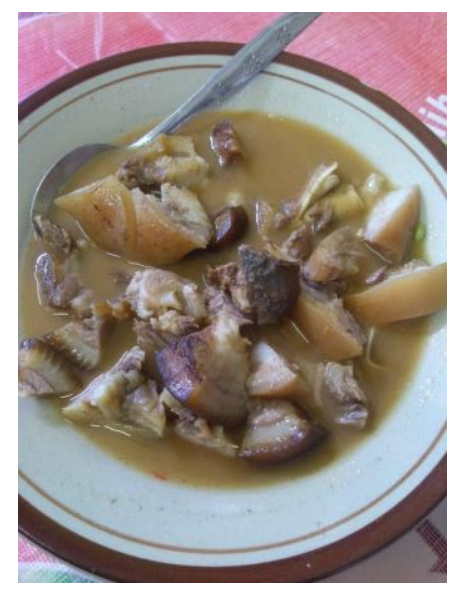

\section{Gambar 5 Sekba}

Gambar sekba di atas peneliti temukan dijajakan dengan gerobak. Peneliti berhasil menemukan gerobak ini berdekatan dengan Bakmi Amoy. Selama turun lapangan, peneliti menemukan 2 gerobak di lokasi yang berbeda. Wujud sekba sudah terbayang berdasarkan gambar yang ada di internet, dan terpampang nyata di hadapan peneliti seperti gambar 7 di atas. Peneliti memilih bagian kuping, pipi, kaki, dan dengkul. Sekba disajikan dengan kuah yang kaya akan rasa. Surprisingly, sekba dan kuahnya memiliki rasa yang enak, manis dan gurih dengan perasan jeruk nipis menambah kesegaran sehingga tidak eneg. Jika menilik sedikit adanya akulturasi maka peneliti mengaitkan rasa kuah dengan rasa salah satu sop kambing legendaris di Blok M. Perpaduan daging atau tulang muda dengan kuah seperti di gambar di atas yang membuat rasa penasaran peneliti semakin besar. Sembari menunggu, peneliti bertanya tentang racikan bumbu, penjual hanya menjawab "racikan mama di rumah". Peneliti dapat melihat campuran kaldu yang berwarna coklat seperti semur ditambah dengan merica dan kecap asin, sekali lagi kecap sebagai bahan utama hidangan Tionghoa menjadi unsur yang harus ada.

Pembahasan terakhir untuk hidangan penutup, bakpia. Bakpia tidak hanya terasosiasi dengan Jogjakarta namun juga dengan sejarahnya hingga bisa masuk ke Indonesia karena pengaruh Tionghoa. Artikel yang ditemukan terkait bakpia menlansir bahwa "pia atau yang lebih dikenal dengan bakpia merupakan kue khas China. Sejarah pia berasal dari China bagian Selatan. Kue ini terbuat dari adonan tepung terigu dan lemak sehingga saat dipanggang renyah dan terasa berlapis-lapis. Adonan kulitnya ada yang sedikit keras dan kenyal serta ada juga yang tipis renyah. Isiannya pun beragam, dari manis hingga gurih. Artikel lain melansir bahwa bakpia di Tiongkok dikenal dengan nama tou luk pia yang bermakna roti dengan isian daging. Bakpia Tiongkok memiliki ukuran yang lebih besar dengan isian berupa daging yang sudah diolah. Bakpia dibawa imigran Tiongkok ke Indonesia dengan resep asli minyak dan isian daging babi. Indonesia yang mayoritas muslim, mendorong imigran ini untuk berinovasi dengan bahan dan isian yang bisa dimakan semua golongan. Imigran lain juga menciptakan varian bakpia seperti yang ada sekarang ini sehingga di Indonesia, lebih 
banyak bakpia dengan isian bahan manis. Bakpia yang peneliti temui di Glodok tergambar seperti di bawah ini:

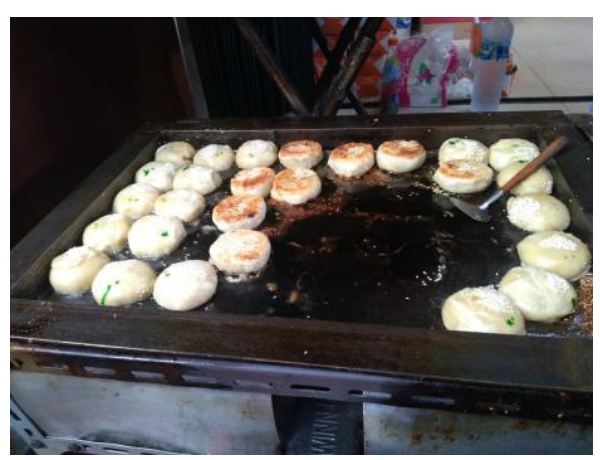

\section{Gambar 6 Bakpia}

Bakpia yang ditemui peneliti di Glodok terlihat sedang dalam proses produksi dengan oven atau pemanggang yang berada di tepi jalan yang ramai sehingga dapat menggugah selera siapapun yang melewatinya. Seperti dituliskan pada artikel di atas, isian bakpia telah bergeser sesuai mayoritas penduduk Indonesia (Jakarta) sehingga varian yang dijual lebih banyak yang manis, yaitu kacang hijau dan durian. Bakpia dengan isian manis tersebut ditaburi wijen dan dipanggang hingga kulitnya kecoklatan. Harga per butirnya 5.000 rupiah, cocok untuk oleh-oleh dari Pecinan.

\section{KESIMPULAN}

Filosofi gastronomi pada makanan kuo tie, bakso, dan bakmi masih melekat. Kuo tie dan bakmi masih harus ada dalam sajian Tahun Baru Imlek. Penjual makanan kuo tie dan bakmi pun berharap akan terus mendapat keberuntungan dari berjualan makanan ini. Originalitas rasa untuk semua makanan (kecuali bakpia) juga masih terasa karena semua masih menggunakan bahan utama daging babi beserta bumbu utama dan rempah khas Tionghoa. Teknik masakan yang jelas masih dipertahankan adalah kuo tie dan sekba. Kuo tie memiliki tingkat kematangan dengan putih kulit kecoklatan menandakan teknik memasak dengan besar api yang harus tepat. Teknik memotong dan memasak pada sekba juga masih sama karena besar kecil potongan, campuran bumbu, dan besar api juga akan mempengaruhi kematangan, rasa, dan aroma masakan. Pergeseran yang jelas terlihat untuk bakpia dimana bakpia yang dijual hanya bakpia manis yang aman untuk dikonsumsi oleh masyarakat Indonesia. Kelebihan pada penelitian ini ada di kesempatan untuk mencoba dan meneliti makanan khas Peranakan Tionghoa yang memang sudah menjadi referensi dari berbagai sumber. Kekurangan pada minimnya informasi yang mau dibagikan oleh produsen makanan. Informasi cenderung "sudah dari dulu seperti itu" sehingga tidak ada celah lagi untuk bertanya lebih lanjut. Pedagang juga fokus pada penjualan bukan pada kepentingan akademis seperti ini. Pengembangan selanjutnya dengan melakukan pendalaman tentang filosofi gastronomi ini dengan melakukan wawancara bersama ahli kuliner Peranakan serta meluas ke multidisiplin yang lain seperti ekonomi dan pariwisata gastronomi. 
Vol 3, No. 1, 2020

\section{UCAPAN TERIMA KASIH}

Penulis mengucapkan terima kasih kepada LPPM Universitas Sahid Jakarta yang telah memberi dukungan financial terhadap penelitian ini. Terimakasih juga untuk para narasumber (penjual makanan) yang telah memberikan informasi pada saat turun lapangan.

\section{DAFTAR PUSTAKA}

Boyne, Steven et al. (2003). Policy Support and Promotion for Food Related Tourism Initiatives.

https://www.researchgate.net/publication/254378989_Policy_Support_and_Promotion _for_Food-Related_Tourism_Initiatives. Diakses 30 November 2018.

Bromokusumo, AK. (2011). Resep Masakan: "Babi Cin”. http://web.budayationghoa.net/index.php/item/619-resep-masakan-babi-cin. Diakses tanggal 30 Juli 2020 .

Gumulya, Devanny. (2017). Pencampuran Budaya Cina, Jawa, dan Belanda pada Budaya Makan Cina

Peranakan. https://publikasi.dinus.ac.id/index.php/andharupa/article/view/135. Diakses tanggal 29 November 2018.

Pujawan, A.A. Ketut Alit dan Trisdayanti, Ni Putu Eka. (2017). Eksplorasi Makanan Tradisional Bali di Kabupaten Bangli. Jurnal Gastronomi Indonesia. No.1. Volume 5 halaman 1-12.

Priherdityo, Endro. (2017). Blusukan Kuliner di Antara Gang Glodok. https://www.cnnindonesia.com/gaya-hidup/20170128012450-262-189632/blusukankuliner-di-antara-gang-glodok. Diakses 20 Januari 2020.

Rama, Febri. (2018). Mengenal Sejarah Bakso, Kuliner Sejuta Umat Selama Berabad-abad. https://travelingyuk.com/sejarah-bakso/80734. Diakses tanggal 20 Januari 2020.

Rohman, Taufigur. (2017). Sejarah Bakpia Pathok, Jajanan Khas Yogyakarta yang Mendunia. https://phinemo.com/sejarah-bakpia-pathok-jajanan-khas-yogyakarta-yang-mendunia. Diakses 17 Agustus 2020.

Sormaz, Umit et al. (2015). Gastronomy in Tourism. https://www.sciencedirect.com/science/article/pii/S2212567116302866. Diakses tanggal 29 November 2018.

Sugiyono, P. (2015). Metode penelitian kombinasi (mixed methods). Bandung: Alfabeta.

Wenhua, Zhonghua. (2012). Jiaozi dan Kuotie. http://web.budayationghoa.net/index.php/item/1666-jiaozi-dan-kuotie. Diakses tanggal 20 Januari 2020.

Wijaya, Yana Gabriella. (2019). Sejarah Bakmi hingga Jadi Favorit di Indonesia. https://travel.kompas.com/read/2019/11/27/111100127/sejarah-bakmi-hingga-jadifavorit-di-indonesia-. Diakses tanggal 20 Januari 2020. 